\title{
PERCEPÇÃO DE DOCENTES DE UM CURSO DE FISIOTERAPIA SOBRE ESTRATÉGIAS DE ENSINO-APRENDIZAGEM APLICADAS NO ESTÁGIO CURRICULAR
}

\author{
PROFESSORS' PERCEPTION OF A PHYSIOTHERAPY COURSE \\ ON THE TEACHING-LEARNING STRATEGIES APPLIED IN \\ THE CURRICULAR INTERNSHIP
}

Marcus Aurélio Medeiros Costa (Orcid: 0000-0003-1570-584X) Francisco José Passos Soares (Orcid: 0000-0002-5872-2183)²

Jorge Artur Peçanha de Miranda Coelho (Orcid: 0000-0002-0021-5963) ${ }^{2}$

Contato

Marcus Aurélio Medeiros Costa

E-mail: marcusamc@yahoo.com.br

${ }^{1}$ Departamento de Fisioterapia, Faculdade Estácio de Alagoas, Alagoas, Brasil.

${ }^{2}$ Faculdade de Medicina, Universidade Federal de Alagoas, Alagoas, Brasil.

\section{RESUMO}

A formação em saúde deve orientar o docente a pautar as práticas pedagógicas e as estratégias de ensino-aprendizagem na promoção da construção de significados aos discentes, resultando em um protagonismo centrado no desenvolvimento da autonomia, da ética e da integralidade. Para a formação do profissional fisioterapeuta, as estratégias de ensino-aprendizagem utilizadas pelos docentes devem corresponder ao que determina as Diretrizes Curriculares Nacionais do Curso de Graduação em Fisioterapia (DCN/Fisio). Este estudo teve como objetivo verificar a percepção de docentes de um curso de graduação em Fisioterapia sobre a adequação das estratégias de ensino-aprendizagem adotadas no estágio curricular em relação às competências gerais e habilidades previstas nas DCN/Fisio. Tratou-se de uma Pesquisa qualitativa, exploratória, do tipo estudo de caso. A coleta dos dados foi realizada em uma Instituição de Ensino Superior privada da cidade de Maceió. Foram entrevistados 15 docentes que compõem a disciplina Prática Supervisionada - Estágio. Utilizou-se como instrumento de coleta de dados a entrevista com questionário semiestruturado. Os dados foram analisados por meio do programa IRaMuTeQ. Foram consideradas quatro classes para análise final dos dados: fragilidades do estágio; o exercício da autonomia e de outros valores na formação profissional; estratégias de ensino e avaliação: desafios para inovação no estágio curricular; modelo de formação: angústias e incertezas. Os resultados diagnosticaram um distanciamento e inadequação entre as estratégias de ensino-aprendizagem adotadas e as DCN/Fisio. As angústias e as incertezas geradas por essa inadequação podem ser enfrentadas por uma política institucional de desenvolvimento e educação continuada com cursos de capacitação pedagógica para os docentes.

Palavras-chave: Educação em Saúde; Ensino superior; Aprendizagem; Estágio Clínico; Fisioterapia.

\begin{abstract}
Health education should guide professors to base their pedagogical practices and teaching-learning strategies in promoting the construction of meanings to students, resulting in a protagonism focused on the development of autonomy, ethics, and integrality. For the training of the physiotherapist professional, the teaching-learning strategies used by the professors must correspond to that determined by the National Curricular Guidelines of the Undergraduation Course in Physiotherapy (DCN/Fisio). The objective of this study was to verify the perception of the professors of an undergraduate course in Physiotherapy regarding the adequacy of the teaching-learning strategies adopted in the supervised internship in relation to the general skills and abilities established in the DCN/ Fisio. This is a qualitative, exploratory research of the type of case study. Data collection was carried out at a private Higher Education Institution in the city of Maceió, in the state of Alagoas. Fifteen professors that are part of the course Supervised Practice - Internship were interviewed. The interview with semi-structured questionnaire was used as instrument of data collection. The data were analyzed with through the IRaMuTeQ software. Four classes were considered for final analysis of the data: internship fragilities; the exercise of autonomy and other values in vocational training; strategies of teaching and evaluation: challenges for innovation in the curricular internship; training model: anxieties and uncertainties. The results diagnose distancing and inadequacy between the political-pedagogical project of training, guided by the NCGP, adopted in the analyzed institution and the teaching practice. The anxieties and uncertainties generated by such inadequacy can be faced with an institutional policy of continuous development through courses of pedagogical training for professors.
\end{abstract}

Keywords: Health Education; Education, Higher; Learning; Clinical Clerkship; Physical Therapy Specialty. 


\section{INTRODUÇÃO}

A formação em saúde, na atualidade, exige que a aprendizagem ocorra nos ambientes de trabalho em que o discente atuará como profissional no futuro. As Diretrizes Curriculares Nacionais do Curso de Graduação em Fisioterapia (DCN/Fisio) orientam para a formação generalista, humanista, crítica e reflexiva, capacitando o discente a atuar em todos os níveis de atenção à saúde, com base no rigor científico e intelectual; obtendo visão ampla e global, com respeito aos princípios éticos/bioéticos e culturais do indivíduo e da coletividade ${ }^{1}$.

De acordo com as DCN/Fisio, o fisioterapeuta deve estar apto a desenvolver ações de prevenção, promoção, proteção e reabilitação da saúde, tanto em nível individual quanto coletivo; assegurar que sua prática seja realizada de forma integrada e contínua com as demais instâncias do sistema de saúde; analisar de forma crítica e buscar soluções para os problemas da sociedade. Os profissionais devem realizar seus ofícios dentro dos mais altos padrões de qualidade, tendo em conta que a responsabilidade da atenção à saúde não se encerra com o ato técnico, mas, sim, com a resolução do problema de saúde, tanto em nível individual como coletivo ${ }^{1}$.

Os docentes, supervisores de estágio, em seus ambientes de trabalho, constituídos como cenários possíveis $\mathrm{e}$ legítimos de ensino-aprendizagem, desempenham a dupla função de assistente e professor. A supervisão do estágio em saúde é uma prática pedagógica que ocor- re no ambiente de trabalho e formação profissional, no momento do exercício clínico, conduzida por profissionais com cargo de professor ou não, com o objetivo de construir e transmitir conhecimentos relativos a cada área de atuação, estimulando os discentes a atuarem no processo saúde-doença-cuidado, em seus diferentes níveis de atenção, com responsabilidade social e compromisso com a cidadania ${ }^{2}$.

Segundo Ribeiro ${ }^{3}$, é desejável que, na etapa do estágio, o docente esteja apto a planejar estratégias capazes de permitir aos discentes: articular conteúdos teóricos com a prática; superar lacunas do conhecimento; assumir responsabilidades com o serviço e comprometer-se com os pacientes - nesse intento, a relação docente-discente é um importante instrumento para a construção do conhecimento. Para que essa relação aconteça de forma proveitosa, é importante que o docente acolha e valorize o que o discente traz enquanto arsenal teórico e de sentimentos. Estimula-se nessa relação o ato de pensar, construindo hipóteses e as ratificando ou retificando de tal modo a assumir novos pressupostos de ensinagem e formação ${ }^{4}$.

$$
\text { O estágio curricular tem im- }
$$
portância fundamental no processo de construção do conhecimento, garantindo ao futuro fisioterapeuta reunir condições técnico-científicas para a autonomia e oferta à sociedade de assistência com rigor científico e humanístico, considerando o contexto biopsicossocial. Visa ao aprendizado de competências próprias da atividade profissional e à contextualização curricular, objetivando o desenvolvimen- 
to do educando para a vida cidadã e para o trabalho ${ }^{5}$.

As estratégias de ensino-aprendizagem utilizadas pelos docentes na supervisão do estágio curricular devem corresponder às competências gerais e habilidades determinadas nas DCN/Fisio: atenção à saúde, tomada de decisão, comunicação, liderança, educação permanente, administração e gerenciamento ${ }^{1,6}$.

O processo de envolvimento entre o docente supervisor de estágio, o discente estagiário, a Instituição de Ensino Superior (IES) formadora, os cenários de prática, as diretrizes curriculares e o Projeto Político-Pedagógico do Curso (PPC) que norteiam a formação do fisioterapeuta compõe a dimensão para fomentar uma política educacional, no sentido de contribuir para a qualidade e a eficiência do processo de ensino-aprendizagem.

Dessa forma, este estudo teve como objetivo verificar a percepção de docentes de um curso de graduação em Fisioterapia de uma faculdade privada de Alagoas sobre a adequação das estratégias de ensino-aprendizagem aplicadas no estágio supervisionado em relação às competências gerais e habilidades previstas nas DCN/Fisio.

\section{METODOLOGIA}

Trata-se de estudo exploratório, com abordagem qualitativa, orientado pelo método de estudo de caso A pesquisa foi realizada em um curso de graduação em Fisioterapia, criado em 2001, de uma IES privada, na cidade de Maceió. Dos 17 docentes que integram a disciplina Prática Supervisionada - Estágio, dos $9^{\circ}$ e $10^{\circ}$ períodos, 15 foram entrevistados. Não participaram das entrevistas uma professora que estava em licença maternidade e um dos pesquisadores responsáveis por este estudo. Os convites para participação foram feitos pessoalmente e formalizados via e-mail. Também se usaram aplicativos de bate-papo e redes sociais para organizar o agendamento dos encontros de acordo com a disponibilidade dos participantes.

Os dados foram coletados por meio de entrevista gravada, entre setembro e novembro de 2017, tendo como guia um questionário semiestruturado composto pelas seguintes questões: quais as estratégias de ensino-aprendizagem são desenvolvidas na sua prática diária na supervisão do estágio? Como você elabora/ planeja as estratégias de ensino-aprendizagem para desenvolver na sua prática diária? Quais são as competências e habilidades gerais que você procura enfatizar para que o aluno as adquira ao longo do desenvolvimento do seu estágio? Em sua opinião, suas estratégias de ensino-aprendizagem são capazes de atender às competências e habilidades requeridas pela DCN/Fisio? Como você identifica, no seu estágio, articulação entre teoria e prática? $\mathrm{E}$ entre ensino, serviço e comunidade? (Exemplifique as articulações encontradas); como ocorre a avaliação do aluno? (Somativa? Formativa?); você trabalha com metodologias ativas no estágio? Quais? Que tipo de feedback é utilizado 


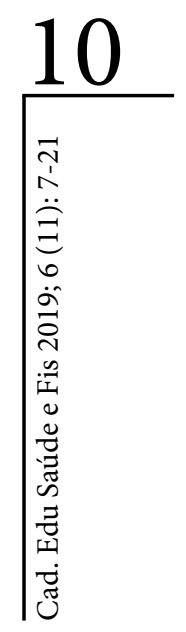

no seu estágio neste processo de ensino-aprendizagem? Quais fortalezas você identifica relativas ao uso de suas estratégias de ensino-aprendizagem no exercício da supervisão do estágio? Quais fragilidades você identifica relativas ao uso de suas estratégias de ensino-aprendizagem no exercício da supervisão do estágio?

Para fins de manutenção do sigilo da identidade, os participantes foram representados pela sigla D (D1, D2, D3...). As entrevistas duraram aproximadamente 40 minutos. As respostas devidamente transcritas foram analisadas pelo programa de análise de dados qualitativos IRaMuTeQ, visando identificar núcleos de significância que, pela sua presença ou frequência, expressam sentidos relacionados com as dimensões das falas dos sujeitos. O IRaMuTeQ decompõe o texto em segmentos de texto e efetua uma classificação em função da distribuição do vocabulário. Inicialmente, a análise estatística efetuada consiste em uma Classificação Hierárquica Descendente (CHD), com o objetivo de calcular as partições em classes lexicais e apresentar suas relações sob a forma de uma árvore (dendograma). Em seguida, efetua-se uma Análise Fatorial de Correspondência (AFC), que permite visualizar, sob a forma de um plano cartesiano, as relações e/ou oposições resultantes da CHD. A análise de texto informatizada efetua a organização do conteúdo estruturado a partir de uma análise estatística em uma CHD. A finalidade da CHD é de estabelecer uma divisão entre as Classes, de forma mais nítida possível. O dendograma permite verificar a relação entre as Classes [ligação forte (proximidade) ou fraca (dis- tanciamento)] e a representatividade de cada Classe, a partir do seu percentual de explicação do corpus avaliado. Contudo, o dendograma elaborado a partir da análise possibilita a compreensão de inter-relação das Classes $^{7-9}$.

Para a definição das classes, foram consideradas aproximações com a teoria do processo ensino-aprendizagem, segundo Thomas et al. ${ }^{10}$, que consideram o currículo como uma experiência educacional planejada, e as estratégias educacionais como um dos passos fundamentais para o desenvolvimento curricular: os conteúdos que são definidos e os métodos que são selecionados devem ser aqueles com maior probabilidade para alcançar os objetivos previamente estabelecidos.

A realização do trabalho foi autorizada pelo Comitê de Ética em Pesquisa da faculdade analisada em 15 de maio de 2017, por meio do parecer de número 2.063.959. Antes da participação e após informações orais e escritas sobre o objetivo e os procedimentos do estudo, todos os participantes deram seu consentimento informado por escrito, assinando o Termo de Consentimento Livre e Esclarecido. Nenhuma informação que permitisse a vinculação dos dados aos participantes individuais foi usada.

\section{RESULTADOS E DISCUSSÃO}

Da interação com os sujeitos da pesquisa, foram produzidos 148 textos, dos quais foram extraídos para análise um total de 875 segmentos textuais. 
Adotando o critério de aproveitamento textual por uma análise padrão proposto pelo pacote do programa IRaMuTeQ e recomendado para respostas longas ${ }^{7}$, do montante de segmentos textuais acima descritos, foram aproveitados 837, correspondendo a $95,66 \%$ do total do corpus. Considera-se tal resultado como um significativo aproveitamento do corpus, tendo em vista que foi superior a $75 \%$.

A princípio, o software construiu seis classes (Figura 1). Todavia, por questões de similitude e intrínseca relação de codependência entre as classes 2 e 3 e entre as classes 4 e 5 , estas foram agrupadas em uma única classe, sendo consideradas apenas quatro classes para análise final dos dados. Com base na seleção das palavras mais características de cada classe, quanto maior o valor do qui-quadrado $\left(\chi^{2}\right.$ $\geq 3,84$ ), maior peso semântico as palavras têm em relação à classe à qual pertencem; dessa forma foram atribuídos termos que funcionam como seus descritores. A Figura 2 descreve o dendograma com recorte de partições em classes lexicais, configurando as quatro classes do estudo.

\section{Classe 1 - Fragilidades do estágio}

Os relatos apontaram para possíveis fatores que contribuem para fragilidade no processo de ensino-aprendizagem no exercício da supervisão do estágio, sendo o tempo de cada ciclo de rodízio de estágio considerado um dos fatores principais que contribuem para não assegurar condições de viabilidade de uma prática eficiente para o aprendizado de um coletivo de discentes ávidos pela vontade de pôr em prática o conhecimento adquirido ao longo do curso.

Os estágios supervisionados do curso analisado funcionam em forma de rodízio em 18 cenários de prática; e o discente fica, em média, oito dias em cada cenário, o que é considerado curto tempo, para maioria dos docentes, como demonstram as falas abaixo:

“... tem uma quantidade de dias que ele tem que passar em cada campo de estágio e o tempo é muito limitado..." D14

Acredita-se que esse é um desafio na educação aplicável a todos os cursos da saúde, como relatado no estudo de Spallek, O'donnell e Yoo ${ }^{11}$, em que se discute, no âmbito da odontologia, o pouco tempo para o desenvolvimento de novas práticas pedagógicas, ao mesmo tempo que deveriam ter mais oportunidade para trabalhar o desenvolvimento do discente. Lucey, Thibault e Cate ${ }^{12}$ consideram o tempo um inimigo no atual ambiente da educação médica, em que os discentes vivenciam estágios curtos de educação por um período predeterminado, usam-no para estudar e para obter pontuações máximas em exames em vez de aperfeiçoar as competências de atendimento ao paciente; nesse contexto, os docentes não conseguem exercer as habilidades necessárias para se engajar em diálogos de orientação com seus discentes. 


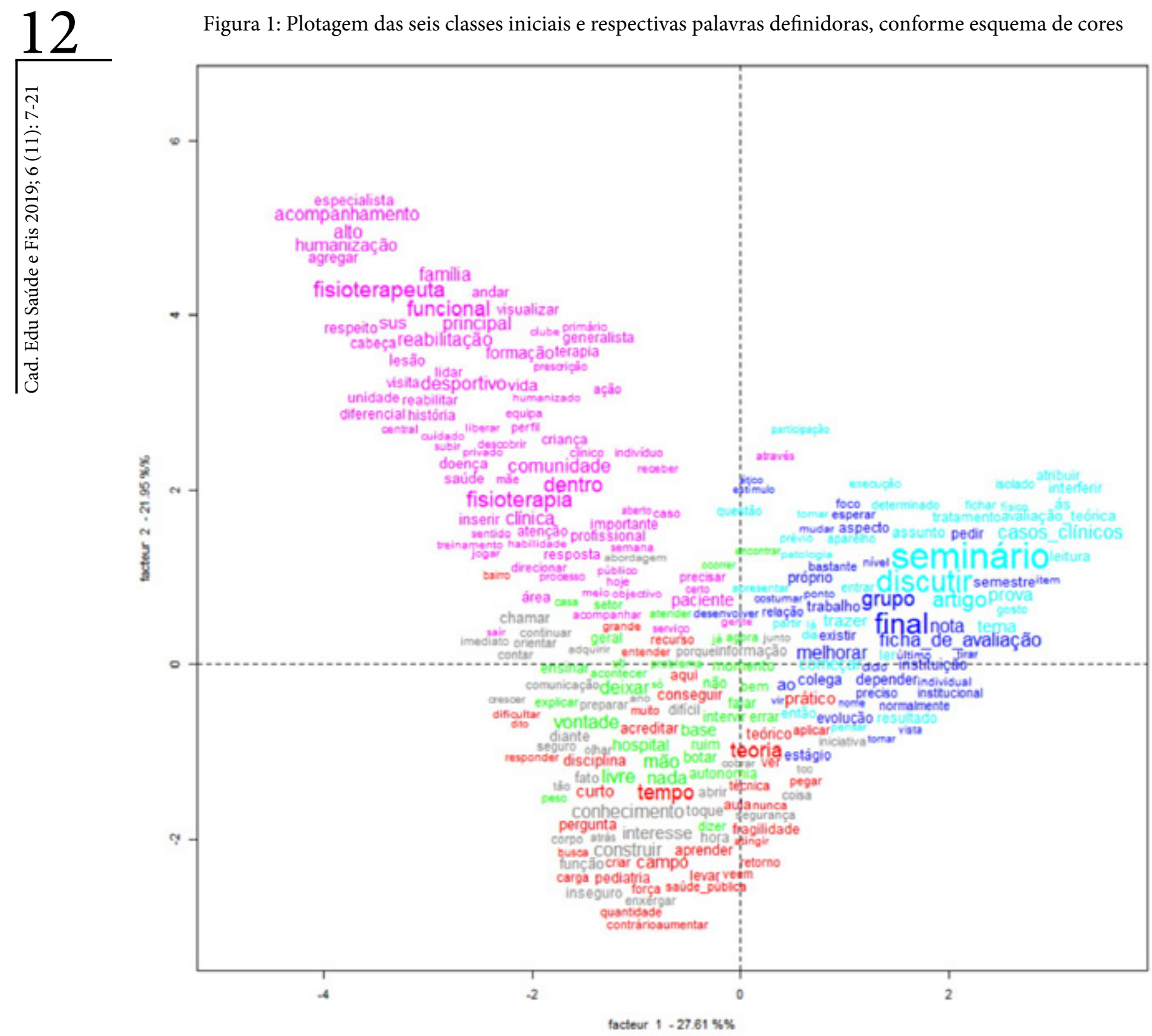

\section{$\begin{array}{llllll}\text { Classe } 1 & \text { Classe } 2 & \text { Classe } 3 & \text { Classe } 4 & \text { Classe } 5 & \text { Classe } 6\end{array}$}

Fonte: Autores, 2018

O tempo limitado para a execução do estágio dificulta o processo de aprendizagem. Tal achado encontra respaldo na literatura, na qual descreve ser possível perceber que o estágio, na formação do fisioterapeuta, deve possuir carga horária que contemple a prática de intervenções preventivas e curativas nos diferentes níveis de atuação: ambulatorial, hospitalar e comunitário. Para tal, os autores afirmam que, para o bom andamento do aprendizado dos discentes, é necessário adequar o tempo, flexibilizar e otimizar as propostas curriculares para enriquecê-las e complementá-las. 
Figura 2: Dendograma com partições em classes lexicais

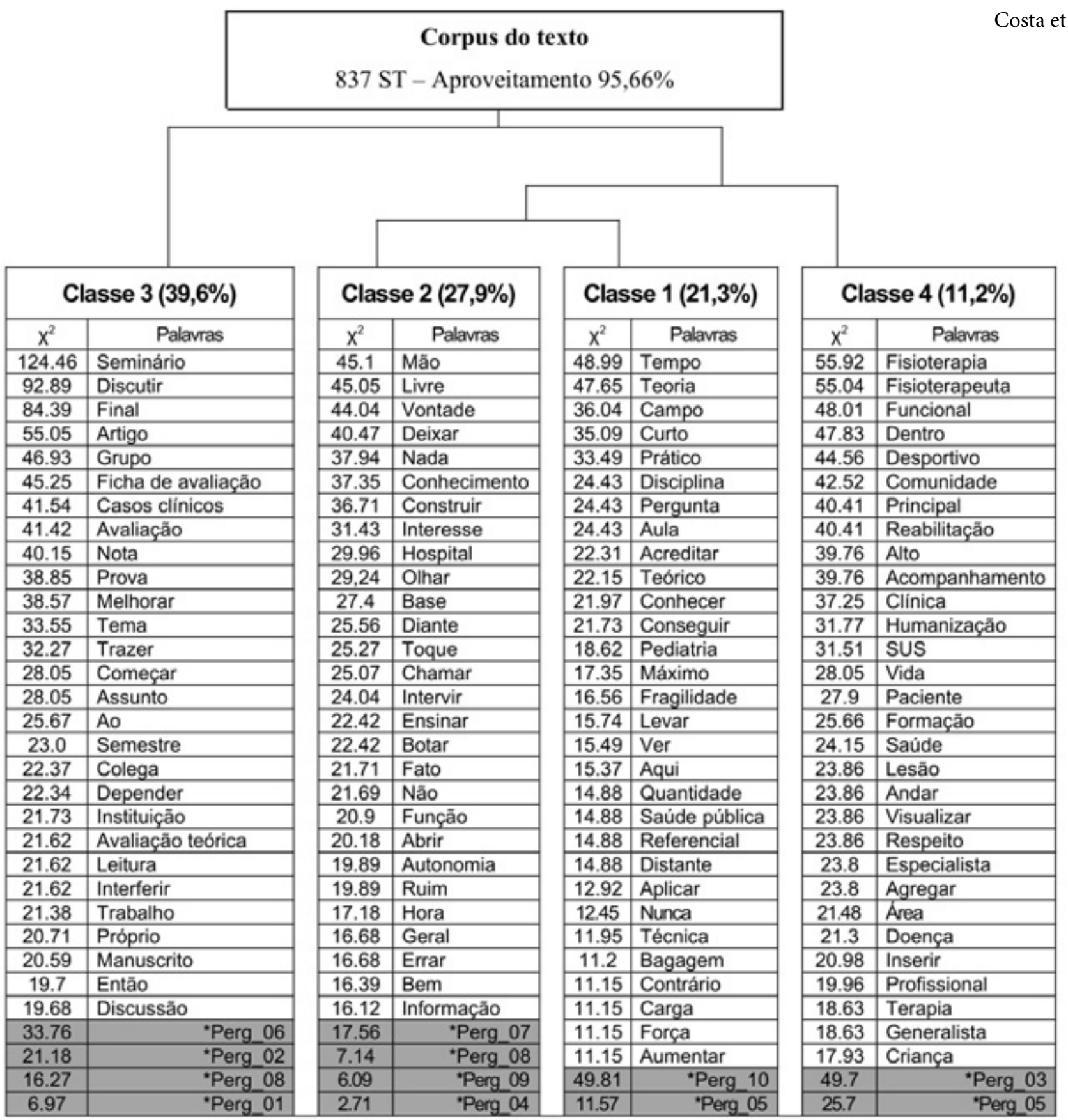

Fonte: Autores, 2018.

Outra fragilidade destacada diz respeito à defasagem entre o conhecimento teórico apresentado pelos discentes e as exigências para a aprendizagem prática própria dos estágios, o que compromete o pleno desenvolvimento das habilidades e competências necessárias ao exercício profissional futuro. O estágio curricular é parte importante do treinamento e aprendizado e deve propiciar ao discente a plena participação em situações reais de vida e trabalho e do meio social. 
“... não consigo ver essa articulação, eles chegam totalmente defasados, que é isso que tenho dito da aproximação teoria e prática”. D6

As práticas em contextos reais possibilitam aos discentes compreender a dimensão do cuidado e os colocam como participantes do processo de trabalho em saúde, permitindo que adquiram habilidade para intervir em variadas situações, muitas delas oportunizadas pela diversidade dos cenários. Assim, as práticas instrumentalizam os estudantes para a atuação profissional em suas diferentes áreas de atuação ${ }^{13}$. Porém, é necessário que se tenha certo grau de domínio teórico, como subsídio, para exercitar a prática com segurança e autonomia perante os problemas reais enfrentados.

Com base nos relatos dos docentes, estes pressupõem que, em algum momento anterior à prática, ainda no âmbito da sua formação, o discente deve demonstrar que domina as habilidades e competências necessárias para a vivência do estágio curricular.

Para a vivência do estágio, no sentido de produzir e incorporar melhores resultados na aprendizagem, o docente deve aperfeiçoar suas práticas pedagógicas a partir do aprofundamento do conhecimento da teoria do processo ensino-aprendizagem. Thomas e $\mathrm{Abras}^{14}$ sugerem que o uso de diferentes métodos educacionais ajuda a superar as dificuldades ao apresentar estratégias de ensino em diferentes formatos para acomodar preferências de aprendizagem. O uso de diferentes métodos educacionais também ajuda a manter o interesse do discente $\mathrm{e}$ oferece oportunidades para recuperação e reforço da aprendizagem, aprofundando-o, promovendo a apreensão do conhecimento e melhora do processo de aprendizagem.

\section{Classe 2 - O exercício da autonomia e de outros valores na formação profissional}

Os docentes, em seus diferentes cenários de prática, demonstraram estimular a autonomia, a segurança e a tomada de decisão diante da realidade vivenciada pelo discente. Cabe ao docente problematizar, mediar e orientar, provocando a tomada de consciência sobre os conceitos implícitos no cuidado e sua respectiva formalização. Conforme Garcia ${ }^{15}$, lidar e problematizar o cotidiano do trabalho é um ato complexo e exige a revisão constante e interdisciplinar. É a interação nos cenários de prática que possibilita essa constituição de sujeitos autônomos, sujeitos de seus projetos, de suas ações e de seu pensar, conhecer e fazer.

“... os deixo livres para buscarem o que precisar, em alguns momentos eu vou estar junto deles e em outros não... vou na casa dos pacientes com eles, apresento, mas tem alguns momentos que os deixo sozinhos, pra eles terem o compromisso". D5 
Outros elementos encontrados nas falas dos docentes dizem respeito à motivação e ao trabalho em equipe.

“Eles não sentem o peso da responsabilidade de apresentar alguma coisa. Eles constroem um conhecimento todos juntos, então ninguém se sente desnivelado... um tá à frente, eu tô mais atrás; então vou ficar calado... não, todo mundo acaba participando". D1

Criar mecanismos que estimulem a motivação pela aprendizagem, de forma que desperte a criatividade, reflexão e resolução dos problemas nos campos de estágio, não é uma tarefa fácil. Estratégias utilizadas na dinâmica ensino-aprendizagem podem não estar contribuindo diretamente para interação entre o discente e o objetivo proposto pelo docente no que se refere à aquisição das habilidades e competências necessárias à formação. Dessa forma, faz-se necessária a compreensão, por parte do docente, do estilo de aprendizagem do discente. Para Sousa et al. ${ }^{16}$, esta tomada de consciência, possivelmente, estaria contribuindo para integrar soluções em relação ao ensino -aprendizagem-motivação

Espera-se que esse modelo de aprendizagem possa ser capaz de: atender às demandas da sociedade; considerar as expectativas, potencialidades e necessidades dos discentes; criar um espaço em que docentes e discentes tenham autonomia para desenvolver o processo de aprendizagem de forma cooperativa, com trocas recíprocas; desenvolver a habilidade de aprender a aprender, em que cada um possa construir o conhecimento, integrando conteúdos e habilidades de forma transdisciplinar e desenvolver diversas capacidades $^{17}$, muitas das quais preconizadas pelas DCN/Fisio, tais como: trabalho em equipe, tomada de decisões, comunicação, liderança e empreendedorismo.

Esses elementos são marcantes na estratégia de ensino e essencial na relação docente/discente, discente/discente e discente/docente/comunidade, devendo ser constantemente exercitados e estimulados nos espaços de aprendizagem. Com isso, busca-se projetar um futuro para a Fisioterapia, somando conhecimento popular e científico, remetendo sempre à história da profissão, seus fundamentos legais e éticos, como preconizam as DCN/ Fisio.

\section{Classe 3 - Estratégias de ensino e avalia- ção: desafios para inovação no estágio curricular}

O PPC do curso em análise orienta para a pluralidade da abordagem metodológica de ensino, mesclando o uso de métodos tradicionais e a prática de metodologias ativas como a problematização e atividades estruturadas em projetos, além de pesquisas, visando à inovação e aperfeiçoamento do processo ensino -aprendizagem. No entanto, observou-se nas falas dos docentes que, no estágio, e provavelmente em todas as etapas do curso, faz-se uma abordagem de ensino usando preferencialmente métodos tradicionais, que não mais se adequam à realidade do mundo do trabalho em saúde. 
“... além dos seminários, temos os manuscritos que eles fazem uma visão crítica daquilo que leem e eu peço, a partir de um tema predefinido, que tragam artigos que vão pesquisar, fazem uma leitura prévia e discutem comigo sobre determinado tema que vou definindo e modificando a cada rodízio que passa”. D14

O cenário internacional vem exigindo que as IES se tornem mais integradas aos assuntos do mundo do trabalho e se comprometam com uma educação com estratégias e práticas inovadoras. Evidenciam-se essas exigências por meio do desenvolvimento de diversificadas e inovadoras estratégias de ensino ${ }^{14}$. A Associação Brasileira de Ensino em Fisioterapia (Abenfisio) vem revelando e divulgando a importância da formação e da educação continuada em saúde e a necessidade da busca de inovação das práticas pedagógicas, sobretudo da articulação entre o sistema de saúde (em suas várias esferas de gestão) e as instituições formadoras ${ }^{6}$.

Para a Abenfisio e o Conselho Federal de Fisioterapia e Terapia Ocupacional (Coffito), o estágio curricular representa um compromisso ético, técnico e profissional, envolvendo todos os atores (IES, serviços de saúde, discentes, docentes, profissionais de saúde, usuários, gestores e sociedade) integrantes do processo de formação em Fisioterapia e em saúde ${ }^{18,19}$.
As DCN/Fisio deveriam funcionar como um guia para nortear as ações docentes para a formação do discente, porém não é o que se observou nas falas da maioria dos sujeitos entrevistados, haja vista ser percebido um significativo desconhecimento do seu conteúdo. Competências e habilidades gerais descritas nas DCN/Fisio, como tomada de decisões, comunicação, liderança, educação permanente, administração e gerenciamento, foram pouco ou quase nada exploradas nos discursos. O exercício dessas habilidades de forma continuada, especialmente no estágio, teria como objetivo garantir a capacitação de profissionais fisioterapeutas com autonomia e discernimento para assegurar a integralidade da atenção e a qualidade e humanização do atendimento prestado aos indivíduos, famílias e comunidades.

Tornou-se uma queixa dos docentes a falta de cursos/treinamentos de atualização e acesso aos novos métodos e estratégias de ensino-aprendizagem oferecidos pela IES; ao passo que consideraram a introdução de novas estratégias de ensino no estágio como um desafio a ser enfrentado. Algo não muito fácil de ser resolvido, pois não depende exclusivamente da vontade dos docentes, mas também de fatores externos, como apoio, estrutura e logística organizacional da IES, na forma de política de desenvolvimento da docência. É relevante que a IES apoie pedagogicamente o profissional para que ele experimente de forma positiva a 
supervisão do estágio, em acordo com os pressupostos do PPC e das DCN/Fisio.

"Tenho as minhas limitações, porque não tenho nenhum curso direcionado à preceptoria em si, sinto essa dificuldade por não ter tido um treinamento específico, um direcionamento melhor". D6

Os relatos também apontaram estratégias avaliativas na prática dos discentes e, de modo geral, estas constam de observação do desempenho do discente em suas atividades práticas e avaliação teórica por meio de prova escrita, seminários, leituras, discussão de artigos e de casos clínicos.

"Avalio se o aluno está realmente estudando para os seminários e os casos clínicos, o desenvolvimento dele do primeiro dia até o último, se conseguiu ter percepção de mudança, de melhora, de adequação de tratamento, e no final faço a prova”. D8

Percebeu-se que os discentes são avaliados pontualmente em cada estágio, sem que haja discussão coletiva acerca da evolução deles; dessa forma, o discente é acompanhando em momentos estanques como se cada estágio fosse único e dissociado do contexto geral que representa o estágio em sua totalidade. A operacionalização da avaliação da aprendizagem ocorre de forma pontual e se apresenta com um caráter unicamente valorativo, ou seja, de forma somativa. Não há desenvolvimento de uma prática que valorize a avaliação formativa, sendo assim, conforme Panúncio-Pinto e Troncon ${ }^{20}$, negligencia-se a formação geral do discente com prejuízo para os aspectos afetivos (atitudinais) e psicomotores (procedimentais), subvalorizando sua importância a longo prazo.

Possibilidades de ressignificação da avaliação no contexto do estágio curricular no curso de fisioterapia pressupõem que as estratégias de avaliação devam estar ajustadas à natureza do conhecimento mais atual às práticas ofertadas nesta etapa de aprendizagem ${ }^{21,22}$. Isso requer um planejamento que integre os objetivos do PPC, o perfil final desejado para o egresso, as metodologias e estratégias de ensino e métodos de avaliação, tendo como referência as competências e habilidades descritas nas DCN/Fisio.

\section{Classe 4 - Modelo de formação: angús-}

\section{tias e incertezas}

As DCN/Fisio estabelecem que o futuro profissional deve desenvolver habilidades e competências técnicas com característica generalista, humana, crítica, autônoma e proativa na busca do exercício da cidadania e do profissionalismo responsável, procurando sempre a inovação em saúde para atender às necessidades da sociedade em que atua. Essas características foram relatadas, de modo ambíguo, pelos docentes entrevistados. 
“... o aluno se identifica com determinada área ou com determinado professor e já quer sair especialista da faculdade. Só que, a formação do fisioterapeuta é generalista e atuando nas três esferas de atenção à saúde”. D10

Os docentes, assumindo de modo individual as atividades em campo, relacionadas com a formação, deram demonstrações de ambiguidade na condução direcionada para o perfil generalista do egresso. Propiciar ao discente uma vivência prática pautada em uma relação ambígua e precária em que inexiste o planejamento conjunto que viabilize a interdisciplinaridade e não se reconhece a integralidade assistencial contribui para uma compreensão limitada do papel do fisioterapeuta na atenção à saúde, indo na contramão das orientações sugeridas nas DCN/Fisio.

As falas dos docentes foram ricas em objetividade e subjetividade, apoiadas em conhecimento pedagógico com características bem definidas: replicam experiências pessoais vividas na graduação e pouco se aventuram nas novas experiências de ensino ofertadas na contemporaneidade. Conforme Gauer et al..$^{23,24}$, cabe ao docente atualizar-se, apropriar-se dos conteúdos e práticas que permitam ampliar a resolutividade das situações de aprendizagem e torná-la mais significativa, como também construir estratégias de ensino-aprendizagem contínuas e planejadas para avançar no processo de reorientação da formação em Fisioterapia.
Os docentes reconheceram a contribuição dos estágios nos diferentes cenários de prática para o melhor desempenho do discente no futuro exercício da Fisioterapia, caracterizando-os como campos de inovação, adaptação e criação.

“... hoje a faculdade está dentro do centro de reabilitação, temos o atendimento específico da fisioterapia, estamos inseridos no programa de estimulação precoce e eles participam das ações de educação continuada...” D6

A proposta dos estágios é a formação profissional que cria espaços para as reflexões entre teoria e prática, cujo objetivo é uma crítica ao vivenciado, identificando demandas dos cenários de práticas. Esse desafio posto aos docentes e aos discentes visa, também, melhor significar o exercício de ser profissional da saúde ${ }^{25}$.

Observou-se uma inquietação dos docentes ante os desafios do mercantilismo na atividade profissional, visto que o discente se encanta com as clínicas especializadas e demonstra desinteresse para os cenários do SUS voltados para a atenção primária e para a saúde coletiva. O docente vê-se pressionado a rever a lógica de formar que atenda aos interesses do mercado de trabalho liberal, para um modelo de formação orientado pelas demandas epidemiológicas e da saúde coletiva. As práticas em diversos cenários devem integrar as áreas básicas e profissionalizantes, ao longo de todo o curso, para garantir uma formação generalista, em consonância com as DCN/Fisio e que atue nos três níveis de atenção em saúde. 
A formação do fisioterapeuta não deve se fixar apenas no desenvolvimento de habilidades específicas, mas na construção de um profissional crítico que, por meio de um processo (re)construtivo, seja capaz de atribuir novos significados à sua prática. Dessa maneira, um ambiente que estimule a discussão e o pensamento crítico é provavelmente mais favorável para promover a maturidade intelectual necessária e o desenvolvimento de habilidades, atitudes e valores ${ }^{26}$.

A redução na angústia e incertezas do ato docente é enfrentada por instituições conscientes do seu papel formador orientado pela responsabilidade social. A identificação das demandas sociais atuais em saúde, considerando-se a epidemiologia regional e local, deve redirecionar os demais aspectos da formação, na qual se inclui também o desenvolvimento docente. Este deve ser motivado a compreender a docência a partir da crítica sobre seu próprio percurso docente institucional, o qual pode ser mais bem compreendido pela pesquisa educacional. A institucionalização de políticas de desenvolvimento docente, pela educação continuada, com aprendizagem sobre a complexa e delicada trama da educação superior em saúde e inclusão também dos aspectos relacionados ao planejamento e à gestão da educação é a via facilitadora de todo esse processo.

\section{CONCLUSÕES}

A reflexão sobre a percepção dos docentes do curso de Fisioterapia sobre as estratégias de ensino-aprendizagem aplicadas no estágio supervisionado, suas fragilidades, potencialidades e as angústias no modelo de formação tornou-se um importante exercício de olhar para o contexto no qual os sujeitos se fazem profissionais. No curso analisado, as estratégias de ensino-aprendizagem nem sempre são consideradas eficazes pelos docentes, uma vez que inúmeros conflitos foram encontrados sem perspectivas de definição de soluções imediatas.

O tempo e as falhas nas etapas que antecedem o estágio foram considerados fatores limitantes à aprendizagem em ambientes complexos de trabalho profissional. Faz-se necessária uma reflexão mais aprofundada sobre o modelo de ensino instituído neste curso de Fisioterapia, de modo a ressignificar ou qualificar sua matriz curricular.

Os docentes consideraram a etapa do estágio como sendo estratégica ao processo ensino-aprendizagem, porém, a falta de conhecimento sobre as DCN/Fisio, norteadoras das ações político-pedagógicas institucionais para a formação do futuro fisioterapeuta, é fonte de angústias e incertezas quanto à garantia da adequação da formação de profissionais de perfil generalista, com autonomia e discernimento para assegurar a integralidade da atenção, qualidade na assistência e humanização do atendimento. Uma política institucional de desenvolvimento docente, 
para a adequação das estratégias de ensino -aprendizagem às DCN/Fisio, ajudará no planejamento da integração ensino-serviço e demais ações que o curso de graduação em Fisioterapia precisa desenvolver para avançar no processo da formação orientada pelas demandas sociais.

O conflito iminente entre promover a formação generalista e humana versus a formação que atenda aos interesses do mercado de trabalho é uma preocupação a ser enfrentada, com desvinculação da formação centrada na assistência individual e mais direcionada à coletividade, visando superar a fragmentação dos modelos curriculares tradicionais para formar profissionais que atentem para os determinantes do processo saúde-doença em todos os níveis de assistência.

\section{REFERÊNCIAS}

1. Brasil. Resolução CNE/CES 4, de 19 de Fevereiro de 2002. Institui diretrizes Nacionais do Curso de Graduação em Fisioterapia. Ministério da Educação, 2002.

2. Missaka H, Ribeiro VMB. A preceptoria na formação médica: o que dizem os trabalhos nos congressos brasileiros de educação médica 2007-2009. Rev Bras Educ Méd 2011; 35(3):303-10.

3. Ribeiro VMB. Formação pedagógica de preceptores do ensino em saúde. Juiz de Fora: Editora UFJF; 2011.

4. Barreto VHL, Monteiro ROS, Magalhães GSG, Almeida RCC, Souza LN. Papel do preceptor da atenção primária em saúde na formação da graduação e pós-graduação da Universidade Federal de Pernambuco - um Termo de Referência. Rev Bras Educ Med 2011; 35(4):578-583.
5. Bombardelli CL, Siliano MR, Guerra ZF. Atualização das Diretrizes Curriculares Nacionais de Fisioterapia: avanço ou retrocesso? Revista Científica CIF Brasil 2017; 9(9):01-12.

6. Associação Brasileira de Ensino em Fisioterapia. Oficinas de implementação das diretrizes curriculares nacionais dos cursos de fisioterapia: Projeto de Cooperação Técnica. OPAS/DEGES/MS - ABENFISIO. Brasília, 2007. Relatório técnico.

7. Camargo BV, Justo AM. IRAMUTEQ: um software gratuito para análise de dados textuais. Temas Psicol 2013; 21(2):513-18.

8. Loubère L, Ratinaud P. Documentation IRaMuTeQ. 2014. [Internet]. [Acessado 2016 mar 18]. Disponível em: http://www.iramuteq.org

9. Reinert M. ALCESTE. Version 4.0 - Windows (Manual). Toulouse: Societé IMAGE; 1998.

10. Thomas PA, Kern DE, Hughes MT, Chen BY. Curriculum development for medical education: a six-step approach. Baltimore: JHU Press. 3rd ed; 2016.

11. Spallek H, O'donnell JA, Yoo YIJ. Preparing faculty members for significant curricular revisions in a school of dental medicine. J. Dent Educ 2010; 74(3):275-88

12. Lucey CR, Thibault GE, Cate O. Competency-based, time-variable education in the health professions : crossroads. Academic Medicine 2018; 93(3):1-5.

13. Benito GAV, Tristão KM, Paula ACSF, Santos MA, Ataide LJ, Lima RCD. Desenvolvimento de competências gerais durante o estágio supervisionado. Rev Bras Enferm 2012; 65(1):172-8.

14. Thomas PA, Abras CN. Step four: educational strategies. In: Thomas PA et al. Curriculum development for medical education: a six-step approach. Baltimore: JHU Press. 3th ed; 2016. p.65-97.

15. Garcia MAA. Saber, agir e educar: o ensino -aprendizagem em serviços de saúde. Interface Comunic, Saúde, Educ 2001; 5(8):89-100. 
16. Sousa AM, Lacerda YC, Barreto JM, Formiga NS, Nascimento RQ. Estilos de aprendizagem em estudantes de fisioterapia de uma instituição pública. [Documento produzido $2014 \mathrm{Fev}$ 08]. [Internet] [Acessado 2018 Jul 14] Disponível em: http://www. psicologia.pt/artigos/textos/A0753.pdf.

17. Waterkemper R, Prado ML. Estratégias de ensino-aprendizagem em cursos de graduação em enfermagem. Av Enferm 2011; 29(2):234-46.

18. Signorelli MC, Israel VL, Gomes ARS, Motter AA, Takeda SYM, Corrêa CL. Um projeto político-pedagógico de graduação em fisioterapia pautado em três eixos curriculares. Fisioter Mov 2010; 23(2):331-40.

19. Araújo FRO, Caldas MAJ, Batiston AP, Neto EN, Ribeiro KSQS, Rocha VM et al. Estágio curricular para os cursos de graduação em fisioterapia: recomendações da ABENFISIO. Fisioterapia Brasil - ABENFISIO 2010; 11(5 - supl):12-15.

20. Panúncio-Pinto MP, Troncon LE. Avaliação do estudante - aspectos gerais. Rev Med (Ribeirão Preto, Online) 2014; 47(3):314-23.

21. Santana TC, Pimenta MAAP. Avaliação no estágio em fisioterapia sob a ótica de professores e estudantes. Meta: Avaliação 2013; 5(15):272-97.

22. Andrade PMO. Avaliação do estágio da fisioterapia conforme as diretrizes curriculares e a perspectiva biopsicossocial da Organização Mundial de Saúde. Avaliação 2010; 15(2):121-34.

23. Gauer APM, Ferretti F, Teo CRPA, Ferraz L, Soares MCF. Ações de reorientação da formação profissional em fisioterapia: enfoque sobre cenários de prática. Interface 2018; 22(65):565-76.

24. Gauer APM, Ferretti F, Teo CRPA. Formação profissional em fisioterapia: entraves para a diversificação dos cenários de prática e integração ensinoserviço. Fisioter Mov 2018; 31:e003128.
25. Forte FDS, Pessoa TRRF, Freitas CHSM, Pereira CAL, Carvalho Junior P. Reorientação na formação de cirurgiões-dentistas: o olhar dos preceptores sobre estágios supervisionados no Sistema Único de Saúde (SUS). Interface 2015; 19(Supl 1):831-43.

26. Reis FJJ, Monteiro MGM. O ensino na Fisioterapia: momento de revermos a prática? Fisioterapia e pesquisa $2015 ; 22(4): 340-1$. 